\title{
Successful treatment of macular holes associated with peripheral retinal vascular tumours
}

G Clare1, D Yorston², DH Charteris

and GW Aylward²

\begin{abstract}
Background Macular holes have been described in association with benign vascular tumours of the retina. However, their successful treatment has not been reported. Patients and methods Three patients with macular holes associated with retinal vascular tumours had vitrectomy, peeling of the internal limiting membrane, and intraocular gas tamponade.

Results In all three cases, the macular holes were successfully closed, and the visual acuity improved.

Conclusion Macular holes associated with benign retinal vascular tumours respond to conventional macular hole surgical techniques. Eye (2007) 21, 419-420. doi:10.1038/sj.eye.6702423; published online 19 May 2006
\end{abstract}

Keywords: macular hole; retinal tumour; retinal glioma; vitrectomy

\section{Case reports}

\section{Case 1}

A 38-year-old woman, who had an isolated retinal angioma in the right eye, presented with a 2-week history of visual loss. The angioma had been treated 8 years previously for macular exudates which regressed. The exudates recurred and she received two additional laser treatments in the 2 months before her presentation. On examination, her visual acuity had declined from $6 / 9$ to $6 / 36$. There was an angioma approximately two disc diameters above the superotemporal arcade and exudates encroaching on the macula (Figure 1a). She had a full-thickness stage III macular hole (Figure 1b) and epiretinal membrane (Figure 1d). The patient underwent right vitrectomy, internal limiting membrane (ILM) peel, injection of $12 \%$ $\mathrm{C}_{3} \mathrm{~F}_{8}$ gas, and cryotherapy and laser to the angioma. She had a plaque adherent to the surface of the angioma that bled slightly when it was avulsed during induction of a posterior vitreous detachment (Figure 1c). Six months later, her right visual acuity was stable at 6/24 and the macular hole was closed (Figure 1e). The exudates had partially regressed.

\section{Case 2}

A 57-year-old woman presented with a 3-month history of poor vision in the left eye. On examination her visual acuity was 6/60. There was a stage IV full-thickness macular hole, and a vasoproliferative tumour in the inferior peripheral retina, surrounded by exudates and shallow sub-retinal fluid. She had a pars plana vitrectomy, with ILM peel and injection of $12 \% \mathrm{C}_{3} \mathrm{~F}_{8}$, and the vasoproliferative tumour was treated with cryotherapy and laser. Six months after surgery, her vision improved to $6 / 24$, the macular hole was closed, and the mass had shrunk with regression of the exudates and subretinal fluid.

\section{Case 3}

A 47-year-old man with noninsulin-dependent diabetes mellitus presented with poor vision in his left eye following uncomplicated cataract surgery. On examination, the left visual acuity was $6 / 18$. There was a vasoproliferative tumour in the inferotemporal retina, and a stage II full-thickness macular hole. There was no evidence of diabetic retinopathy. He had a pars plana vitrectomy with ILM peel and injection of $\mathrm{C}_{3} \mathrm{~F}_{8}$ gas. Six weeks after surgery, the macular hole was closed and the vision improved to $6 / 6$ with a pinhole.

\section{Comment}

Isolated peripheral retinal angiomas and vasoproliferative tumours of the retina (VPTR)
${ }^{1}$ Department of Ophthalmology, Hillingdon Hospital NHS Trust, Uxbridge, UK

${ }^{2}$ Vitreo-Retinal Service, Moorfields Eye Hospital, London, UK

Correspondence: D Yorston Tennent Institute of Ophthalmology, Gartnavel Hospital, 1053 Great Western Road, Glasgow G12 OYN, UK Tel: + 441412111041 ; Fax: + 441412112054 . E-mail: dhyorston@ enterprise.net

Received: 2 December 2005 Accepted: 2 April 2006 Published online: 19 May 2006

None of the authors has a proprietary interest in this case, nor are they in receipt of financial support 

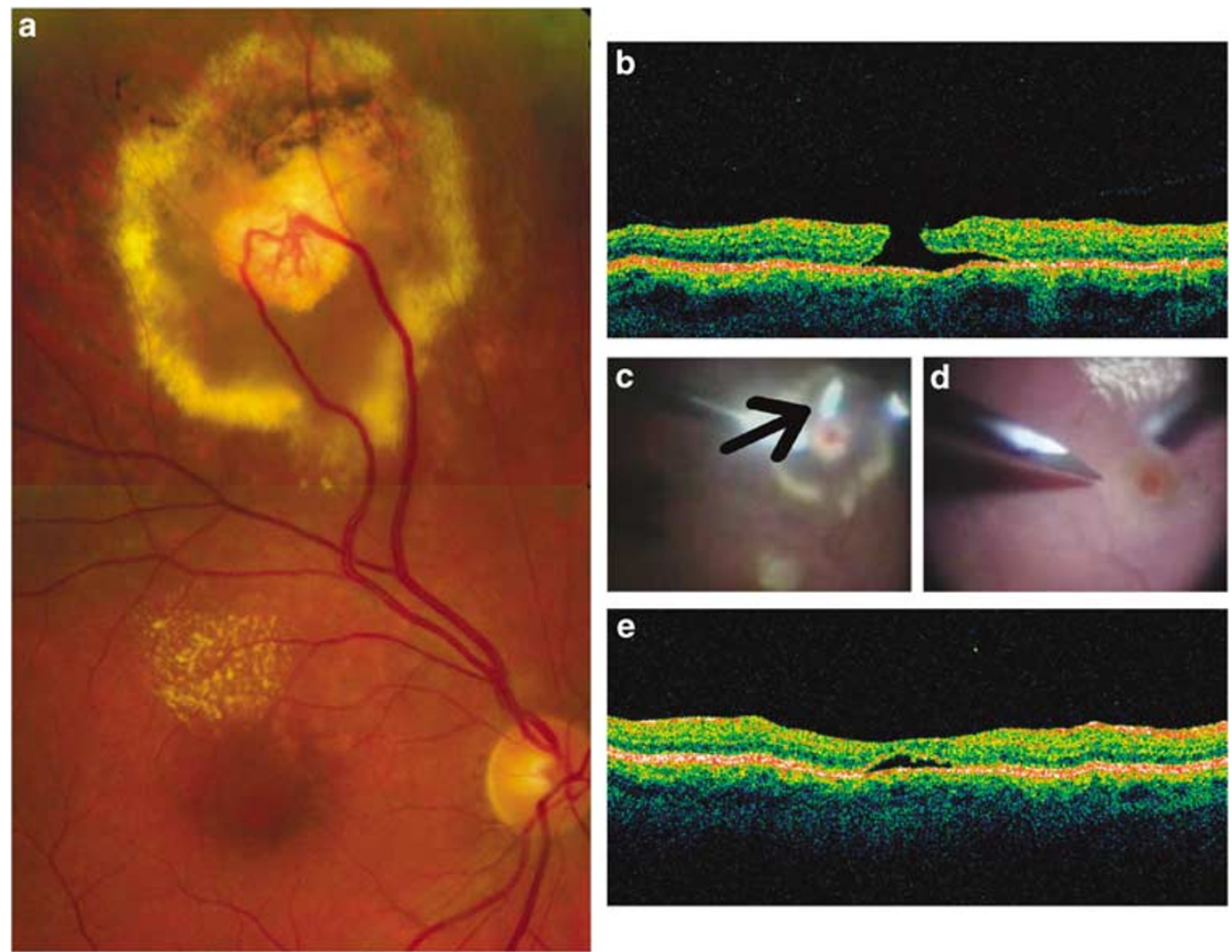

Figure 1 (a) Colour fundus photograph of right eye with isolated retinal angioma, surface neovascularization, drainage and feeder vessels, and surrounding lipid exudates. (b) Optical coherence tomogram of right macula showing full-thickness hole. (c) Intraoperative video still showing avulsed plaque (arrow) and bleeding on surface of angioma. (d) Intraoperative video still showing epiretinal membrane and macular hole stained with trypan blue. (e) Optical coherence tomogram showing closed macular hole, with residual subfoveal fluid, after vitrectomy and gas.

are benign glial lesions, which have in common telangiectasia and leakage of lipid and protein exudate. ${ }^{1-3}$ They are to be distinguished from haemangiomas associated with von Hippel-Lindau disease, which none of our patients had. Epiretinal membrane formation, macular pucker, cystoid macular oedema, and macular hole ${ }^{4}$ may all occur with these lesions, as can tractional macular detachment. ${ }^{5}$ The association between benign peripheral vascular lesions and these findings suggests that pathological changes occur specific to the macula. ${ }^{6}$ Laser treatment for peripheral retinal lesions can itself, over a period of time, be associated with retinal gliosis affecting the macula. ${ }^{7}$

It has been suggested that peripheral retinal telangiectasis with chronic exudate could cause vitreomacular traction resulting in the formation of a fullthickness macular hole. ${ }^{8}$ The mechanism remains unclear, but the authors suggest constitutional changes within the vitreous and the posterior hyaloid face.

This is the first case series report of the successful treatment of macular hole associated with benign peripheral vascular retinal lesions.

\section{References}

1 Shields CL, Shields JA, Barrett J, De Potter P. Vasoproliferative tumours of the ocular fundus.

Classification and clinical manifestations in 103 patients. Arch Ophthalmol 1995; 113: 615-623.

2 Heimann H, Bornfeld N, Vij O, Coupland SE, Bechrakis NE, Kellner $\mathrm{U}$ et al. Vasoproliferative tumours of the retina. $\mathrm{Br} \mathrm{J}$ Ophthalmol 2000; 84: 1162-1169.

3 Singh AD, Shields CL, Shields JA. von Hippel-Lindau disease. Surv Ophthalmol 2001; 46: 117-142.

4 Raju B, Majji A, Jalali S. von Hippel angioma in South Indian subjects - a clinical study. Retina 2003; 23: 670-674.

5 McDonald HR, Schatz H, Johnson RN, Abrams GW, Brown GC, Brucker AJ et al. Vitrectomy in eyes with peripheral retinal angioma associated with traction macular detachment. Ophthalmology 1996; 103: 329-335.

6 Wise GN, Wangvivat $Y$. The exaggerated macular response to retinal disease. Am J Ophthalmol 1966; 61: 1359-1363.

7 Rosa Jr RH, Goldberg MF, Green WR. Clinicopathologic correlation of argon laser photocoagulation of retinal angiomas in a patient with von Hippel-Lindau disease followed for more than 20 years. Retina 1996; 16: 145-156.

8 Jaycock PD, Thomas D, Zakir R, Laidlaw DAH. Retinal telangiectasis in association with macular hole formation. Eye 2004; 18: 342-343. 